\title{
Evaluation of Selected Anthropometric and Cardiovascular Parameters in Pregnancy
}

\author{
${ }^{1}$ Asemota K. E., ${ }^{2}$ Ehebha S. E., ${ }^{3}$ Uyovwiesevwa A. J. and ${ }^{3}$ Gbagbeke K \\ ${ }^{1}$ Department of Human Physiology, Faculty of Basic Medical Sciences, College of Medicine, Ambrose Alli \\ University, Ekpoma, Edo State, Nigeria. \\ ${ }^{2}$ Department of Human Anatomy and Cell Biology, Edo University, Iyamho, Edo State, Nigeria. \\ ${ }^{3}$ Department of Human Physiology, Faculty of Basic Medical Sciences, College of Health Sciences, Delta \\ State University, Abraka, Delta State, Nigeria.
}

\section{Email: asemotaenoma@yahoo.com osgiedeprof@yahoo.com}

\author{
(Received on Date: 13 $3^{\text {th }}$ August 2020 Date of Acceptance: $31^{\text {st }}$ August 2020 Date of Publish: 04 ${ }^{\text {st }}$ September 2020 )
}

\section{ABSTRACT}

For decades now, anthropometric and cardiovascular changes are proven reliable indicators of maternal and child health during pregnancy. In this study, we ascertained the relationship between selected anthropometric [Weight, Height, Body Mass Index (BMI), Head Circumference, Waist Circumference, Hip Circumference and Waist-Hip Ratios] and cardiovascular [Systolic, Diastolic and Mean Arterial Blood Pressures (SBP, DBP and MAP), Pulse Rate (PR)] health indicators for pregnant mothers at different trimesters. Seventy-five (75) pregnant women who registered with the antenatal unit of the central hospital, Warri, Delta State, Nigeria were ethically recruited for the study. The women were then grouped into three (3) of twenty-five (25) subjects each. Grouping was based on their gestational age (Group A = within the First Trimester, Group B = within the Second Trimester, and Group C = within the Third Trimester of pregnancy), and each subject were weekly assessed for the above cardiovascular and anthropometric variables. Using the student t-test, we observed a statistically significant increase $(p<0.05)$ in anthropometric variables across groups as gestational age increased. This was however different for Height, BMl and Head Circumference. In addition, a statistically significant increase ( $\mathrm{p}<$ 0.05) was returned for all cardiovascular parameters as pregnancy age increased per week. However, Pearson Product moment correlation coefficient returned no significant relationship between anthropometric and cardiovascular health indicators across groups with recourse to pregnancy age. More studies that corroborate the results from current 
study are recommended.

Keywords: Pregnancy, Trimester, Anthropometry, Cardiovascular

\section{INTRODUCTION}

Also known as gestation. Pregnancy is a period during which one or more offspring develop inside a woman $[1,2]$. The process begins at fertilization when a male's sperm inseminates a female's ovum (egg), and the fertilized ovum implants in the lining of the uterus $[3,4]$. Though multiple definitions exist for the "initiation of pregnancy", Healthcare providers normally count the initiation of pregnancy from the first day of the woman's lastmenstrual period. This choice is a result of hopelessness to determine the point in time when the actual conception happened. Thus, in in vitro fertilisation, gestational age is calculated by days from oocyte retrieval +14 days (the 14 days before the known time of conception) [2].

In recent times, neonatal deaths and stillbirths reportedly stem from poor maternal health, inadequate care during pregnancy, inappropriate management of complications during pregnancy and delivery, poor hygiene during delivery and the first critical hours. Several factors such as women's cardiovascular health status in society, their nutritional status at the time of conception, early childbearing, too many closely spaced pregnancies, and harmful practices are deeply rooted in the cultural fabric of societies and affect pregnancy in ways that are not always clearly understood [5].
Currently, Obesity in pregnancy is a major health problem across the globe [6]. In the past 20 years, prevalence of Obesity in pregnancy has doubled, leading to a wide range of complications in pregnancy. To envisage and manage this condition, clinicians and other health practitioners adopt changes in cardiovascular and anthropometric health indicators in diagnosing and monitoring events/circumstances as pregnancy proceeds [6].

Maternal low birth weights have long been debated as one of the causes of complications in pregnancy, and is often associated with the death of many new-born infants but is not considered a direct cause [7]. Around 15\% of new-born infants weigh less than 2500g, the proportion ranging from $6 \%$ in developed countries to more than $30 \%$ in some parts of the world. In developing countries, the risk of neonatal deaths during pregnancy are often traceable to complications from maternal health, and is reported to be six times greater than in developed countries; in the least developed countries it is over eight times higher. With 41 neonatal deaths per 1000 live births, the risk of neonatal death is highest in Africa; the sub-Saharan regions of Eastern, Western and Central Africa have between 42 and 49 neonatal deaths per 1000 live births. South-central Asia, with 43 neonatal deaths per 1000 live births, shows rates close to those registered in sub-Saharan Africa, while the neonatal 
mortality rate for Latin America and the Caribbean is 15 per 1000 live births $[8,9]$.

The main "culprit" of maternal cardiovascular and anthropometricbased health hurdle is preterm birth and the complications stemming from it. There is, however, no doubt that maternal health and nutrition before, and at conception are important determinants of weight at birth, neonatal health and frequency and severity of complications, and may contribute to adverse pregnancy outcomes and thus to mortality [10].

\section{Aim of Study}

Current study evaluated selected anthropometric and cardiovascular health parameters in pregnancy. Specifically, study;

i. Ascertained the effects of changes in selected cardiovascular health markers on gestational age

ii. Ascertained the effects of changes in selected anthropometric health markers on gestational age

iii. Compared cardiovascular and anthropometric variables for pregnant women at different trimesters

\section{Materials and Methods}

\section{Study Group}

Study group was made of sixty (60) pregnant women who attended Antenatal care in central hospital labour ward, Warri, Delta State, Nigeria. The women in the study group were aged 17 to 41 years, and were grouped into three groups of twenty (20) women per group; Group A = within the First Trimester, Group $\mathrm{B}=$ within the Second Trimester, and Group $\mathrm{C}=$ within the Third Trimester of pregnancy.

\section{Ethical Clearance}

Ethical approval was sourced from the management board ethics committee of the central hospital, Warri with written inform consent for subjects' participation. All necessary information was then obtained from each women in the study group.

\section{Selection Criteria}

Women with no comorbidities, especially of cardiovascular source were included for participation. Those with health problems liked diabetes, preeclampsia, and anaemia as immune dysfunction were excluded from the study. Cases of congestive heart failure, hypertension, cardiac arrhythmias, etc. were excluded as well.

\section{Methodology}

\section{Collection of Data}

Determination of Cardiovascular Parameters

Pregnant mothers were required to rest in a quiet atmosphere for 30 minutes prior to assessment and recording. This was necessitated by the need to ensure that the cardiovascular variables of interest settle to resting values which may be altered by any noisy activity [11, 12].

\section{Blood Pressure (BP)}


Resting systolic and diastolic blood pressures (SBP and DBP) were measured by means of oscillometry, using the electronic sphygmomanometer with a blood pressure cuff that covered the preferred limb (right arm). The cuff was applied to the upper arm (left or right) of the women at a sitting, standing and lying positions with average taken after three different repetition.

\section{Heart Rate (HR)}

The heart rate was concomitantly recorded (in beats per minute) from the sphygmomanometer reading during blood pressure measurement $[13,14]$.

\section{Pulse Pressure}

This was calculated by subtracting the diastolic blood pressure from the systolic blood pressure (PP = SBP - DBP).

\section{Mean Arterial Pressure (MAP)}

This was obtained from the sum of diastolic pressure and one-third of pulse pressure (DBP+1/3PP).

\section{Determination of Anthropometric Parameters}

For all subjects, the methods described by the American College of Sports Medicine (2010) were used to obtain height, weight, waist and hip circumferences [12]. All anthropometric measurements were performed with the women in lying positions.

\section{Height}

Subjects' Heights were measured in meters to the nearest $0.5 \mathrm{~cm}$ using a balanced stadiometer with participants wearing light clothing without shoes and the shoulders in relaxed position, the arms hanging freely, and the heels and occiput touching the meter rod.

\section{Weight}

Participants' weights were measured in kilogram $(\mathrm{kg})$ to the nearest $0.1 \mathrm{~kg}$ using a weighing scale /Cardinal Scale Manufacturing Co., Webb City, $\mathrm{MO}$ ) with the subjects in light clothing and without shoes.

\section{Body Mass Index (BMI)}

The body mass index (BMI) of the subjects was determined using the formula advanced by Wilmore and Costill (2004); BMI = Weight $(\mathrm{kg}) /$ Height $^{2}$ (meter) [15].

\section{Waist and Hip Circumference}

Waist and hip circumferences were obtained as close to the skin as possible using a flexible and non-elastic tape. Both were recorded to the nearest $0.5 \mathrm{~cm}$ with participant on light clothing.

\section{Waist-Hip Ratio (WHR)}

The waist to hip ratio was calculated by dividing the waist circumference (in centimeters) by the hip circumference (in centimeters) as described by Wilmore and Costill (2004) [15].

\section{Statistical Analysis}

Results were expressed as mean \pm SEM. Student's T-test was used to analyse the significance of the results, comparing the differences in mean in any case. The difference between mean was considered significant at $p<0.05$. 


\section{Results}

Figure I: Comparative Changes in Systolic, Diastolic and Mean Arterial Pressures by Trimester of Pregnancy

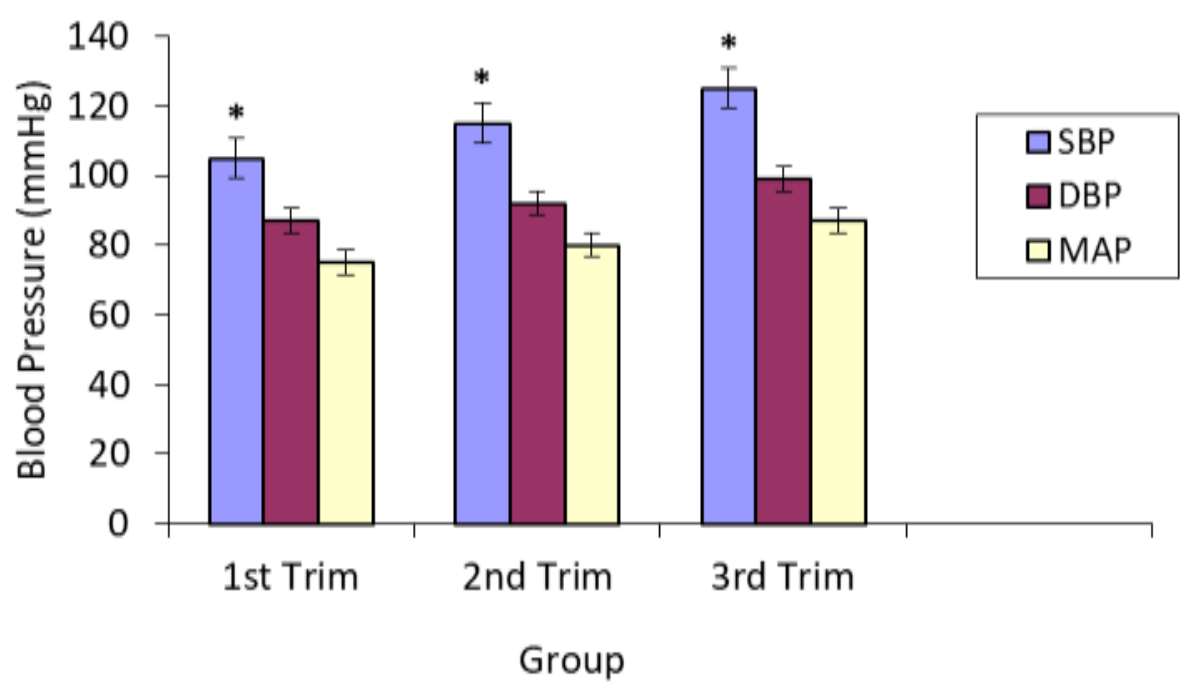

$S B P=$ Systolic Blood Pressure, DBP = Diastolic Blood Pressure, $M A P=$ Mean Arterial Pressure $*$ = significant increase $($ at $p<0.05)$ in $S B P, D B P$ and $M A P$

Figure II: Comparative Changes in Pulse Rate by Trimester of Pregnancy 


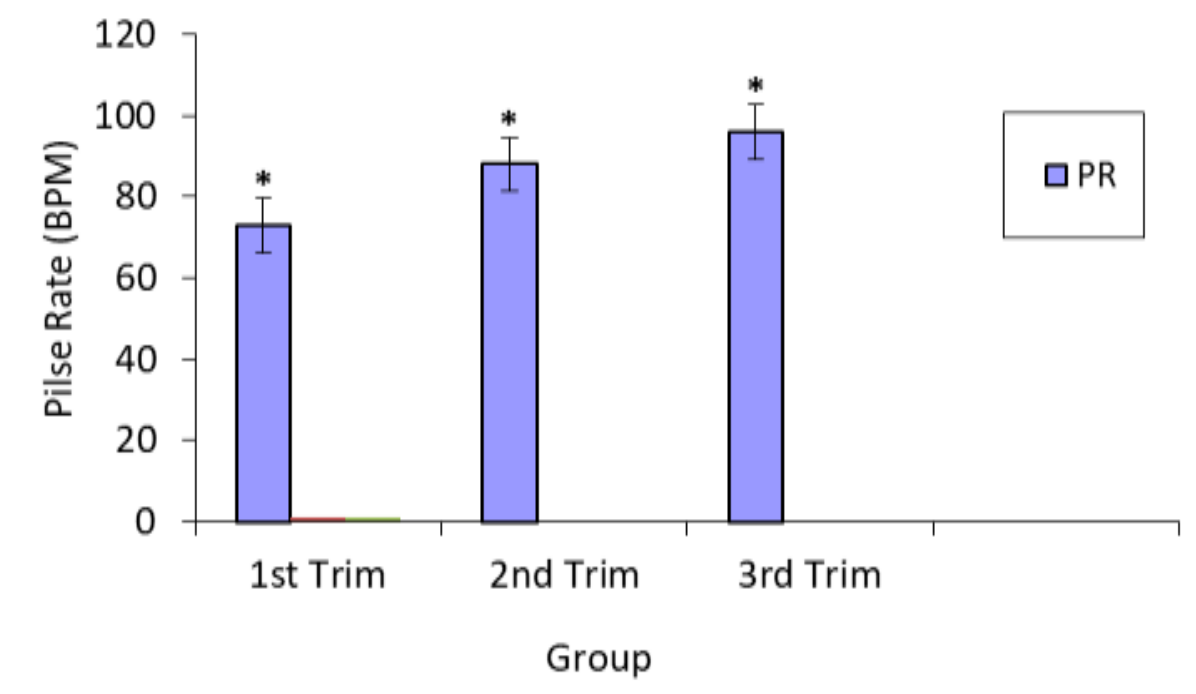

$P R=$ Pulse Rate

* = significant increase $($ at $p<0.05)$ in PR with increased Pregnancy age

Figure III: Comparative Changes in Body Weight by Trimester of Pregnancy

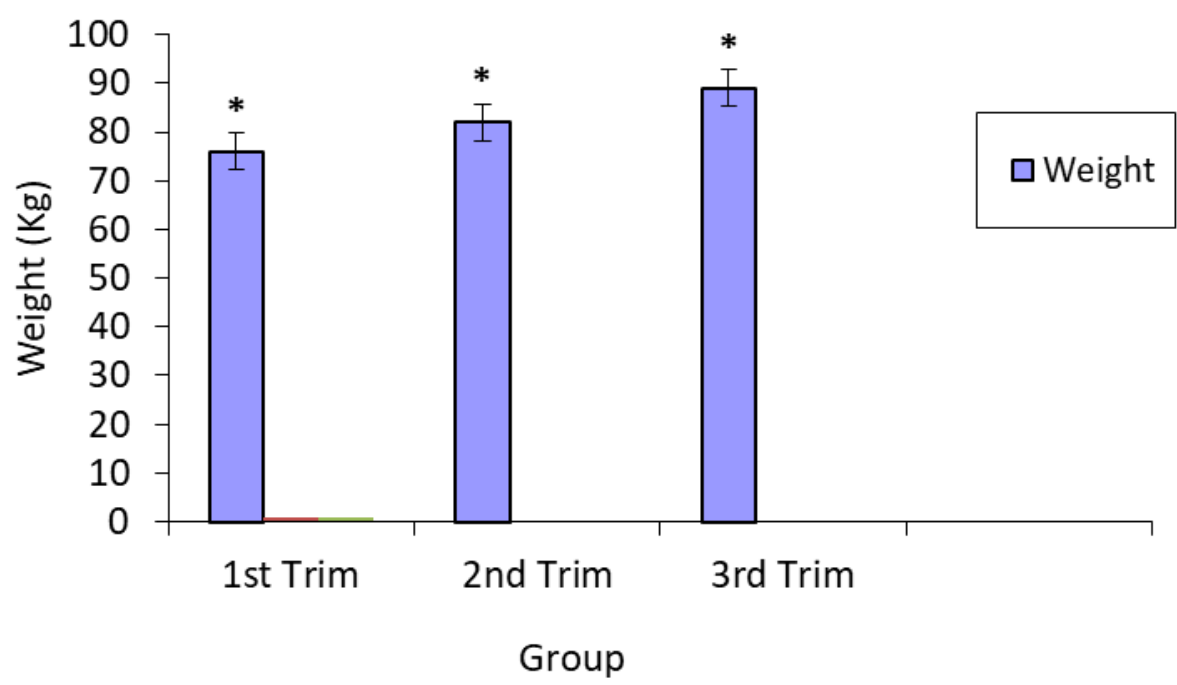

* = significant increase (at $p<0.05)$ in Body Weight with increased Pregnancy age 
Figure IV: Comparative Changes in Height by Trimester of Pregnancy

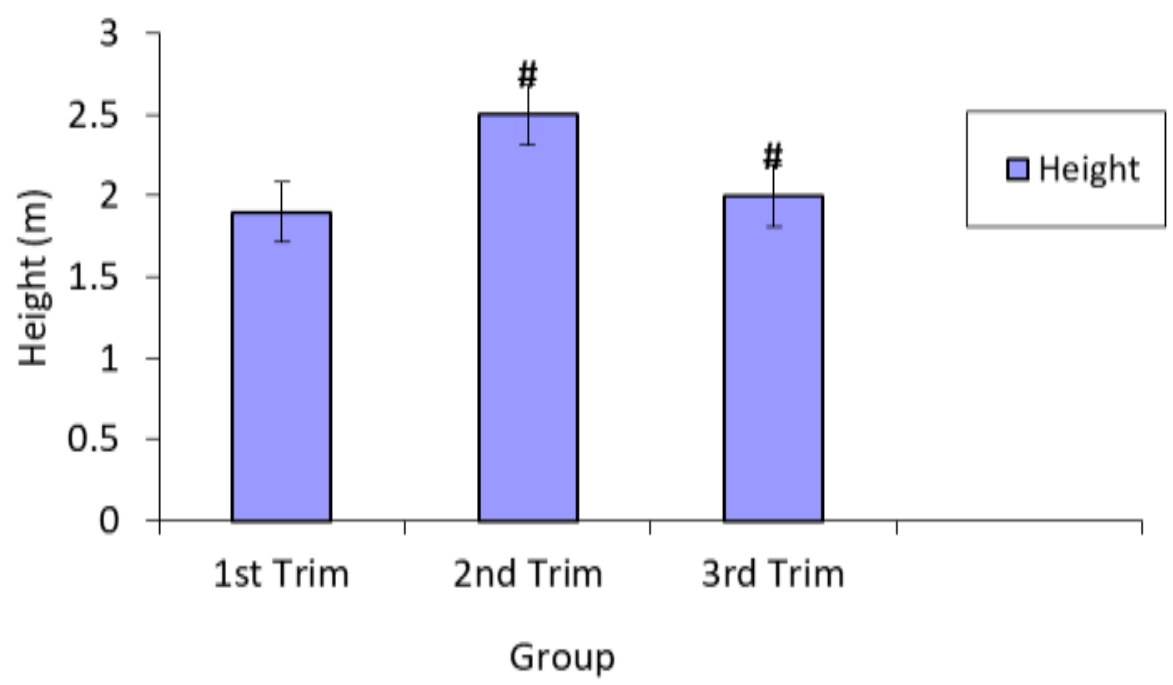

\# = Insignificant increase (at $p<0.05)$ in Height with increased Pregnancy age

Figure V: Comparative Changes in HC, WC and HipC by Trimester of Pregnancy

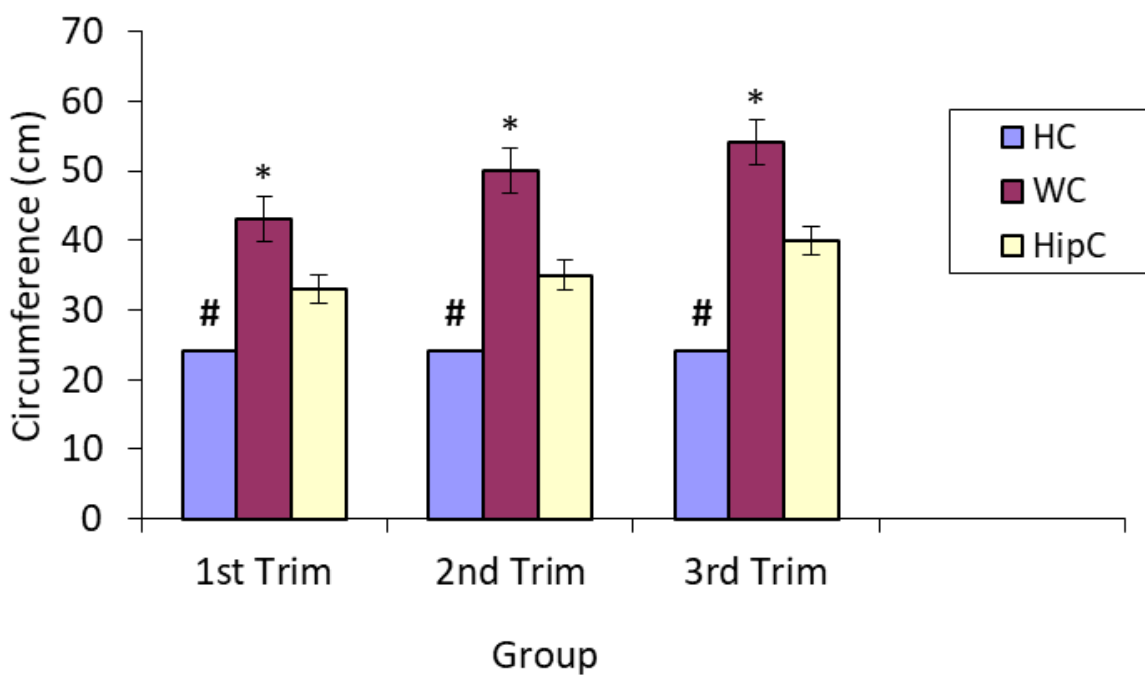

HC $=$ Head Circumference, $W C=$ Waist Circumference, HipC $=$ Hip Circumference

* = significant increase, $\#=$ Insignificant increase $($ at $p<0.05)$ 
Figure VI: Comparative Changes in Hip-Waste Ratio by Trimester of Pregnancy

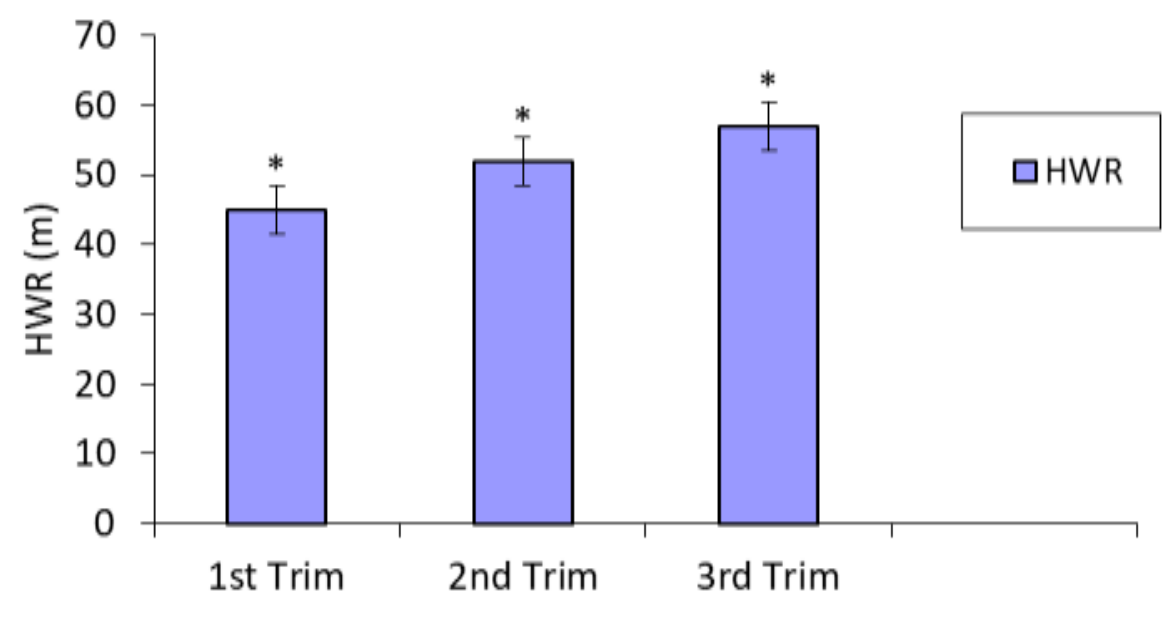

Group

* = Significant increase (at $p<0.05)$ in HWR with increased Pregnancy age

\section{Discussion}

This study investigated the relationship between selected cardiovascular and anthropometric parameters in pregnant women at different gestational ages (trimesters). Sixty (60) gravida (Pregnant women) at different gestational ages were ethically recruited from the central hospital, Warri, Delta State, Nigeria for the study. For each subject, selected anthropometric [Weight, Height, Body Mass Index (BMI), Head Circumference, Waist Circumference, Hip Circumference and Waist-Hip Ratios] and cardiovascular [Systolic, Diastolic and Mean Arterial Blood Pressures (SBP, DBP and MAP), Pulse Rate (PR)] health indicators were obtained weekly and compared using the graph pad prism version 8. From the results obtained from this study, a statistically significant increase $(p<0.05)$ in anthropometric variables across groups as gestational age increased. This was however different for Height, BMI and Head Circumference. Also, a statistically significant increase $(p<0.05)$ was returned for all cardiovascular parameters as pregnancy age increased per week. This implies that maternal cardiovascular parameters increased as foetus developed in-utero. However, Abdulrahman et al., (2001) reported that Nigerian gravida had increased cardiovascular activities with increased gestational age. This negates the findings from this current study.

Blood pressure is one of the commonest clinical methods of assessing circulatory status of humans. In the study, Systolic, Diastolic and mean Arterial pressures (SBP, DBP and MAP) were assessed and compared for term and preterm neonates. Comparative difference in MAP significantly increased by trimester also. Thus, it can be deduced that SBP and MAP are key cardiovascular health markers were higher in third than 
first and second trimesters. DBP is apparently more crucial, and therefore having this lowering ability is more beneficial.

Considering the above, it would be correct to assert third trimester gravida have a more chaotic (or less linear) cardiovascular function behaviour than those in second and first trimesters, since the former, who have no well-balanced sympathetic-parasympathetic systems, can also be considered "less healthy" within the concept of health disease. This logic is explained easily because some intrinsic or extrinsic factors must occur to justify delivery before the term (37 weeks). It is also expected that different age groups and the presence or absence of comorbidities change the results of the assayed variables (SBP, DBP and MAP) used in assessing the standard cardiovascular patterns in this study. This finding concurs with previous reports of Huikuri et al., (2003) [16, 17].

Pulse Rate PR has been reported to significantly affect cardiovascular function and is a vital marker for a gravida's cardiovascular risk assessment (Athanase et al., 2017). According to Athanase et al (2017) in their study titled 'Longitudinal Changes in Mean and Pulse Pressure (PR), and All-Cause Mortality [18]. In this study, PR was seen to have significantly increased ( $p<0.05$ ) in third than second and first trimester gravida (Figure II). This depicts its immense benefit in reducing cardiovascular risk as more blood is easily delivered to the neonate inutero. This also corroborate the study of Mughal et al. (2001) which showed increased PP [19].

\section{Conclusion}

This study has shown that non-BMl indices like waist and hip circumference, Head Circumference, Waist/hip ratios, and cardiovascular health indicators; Systolic, Diastolic and Mean Arterial Blood Pressures, as well as Pulse Rate (PR) have positive relationship with the weight of any gravida, especially with increasing gestational age. This may prove helpful than BMI measurements in the bid to ascertain the onset of obesity and cardiovascular health complications during pregnancy.

\section{References}

1. Pregnancy:

Condition Information".http://www.nichd.nih. gov/. December 19, 2013. Retrieved 14 March2015. External link in | website $=$ (help)

2. Tunón K, Eik-Nes SH, Grøttum P, Von Düring V, Kahn JA (2000). "Gestational age in pregnancies conceived after in vitro fertilization: a comparison between age assessed from oocyte retrieval, crown-rump length and biparietal diameter". Ultrasound Obstet Gynecol 15 (1): 41-6.

3. Lama Rimawi, MD (22 September 2006). "Premature Infant". Disease \& Conditions Encyclopedia. Discovery Communications, LLC. Retrieved 16 January 2008.

4. Nucci LB, Schmidt MI, Duncan BB, Fuchs SC, Fleck ET, Santos Britto MM. Nutritional status of pregnant women: prevalence and Innovative Association 
associated pregnancy outcomes. Rev Saúde Pública 2001; 35:502-7.

5. Fikree. FF, Azam SI, Berendes HW. Time to focus child survival programmes on the newborn: assessment of levels and causes of infant mortality in rural Pakistan. Bull World Health Organ 2002; 80:271-6

6. Bachrach A. (2006). Missed Conception: a call for "Positive" family planning. Medical Journal of Australia. 184: 358-360.

7. Chapman MG, Driscoll GL, Jones B. (2006) Missed conceptions: The need for Education Medical Journal of Australia. 185: 361-362

8. World Health Organization. Physical status: the use and interpretation of anthropometry. Geneva: World Health Organization; 1995.

9. Bachrach A. (2006). Missed Conception: a call for "Positive" family planning. Medical Journal of Australia. 184: 358-360.

10. Campbell S, Lees C. eds. (2000). Obstetrics by ten Teachers. Arnold. London. $7^{\text {th }}$ Edition. 45-66.

11. American College of Sports Medicine. (2006). ACSM'S guidelines for exercise testing and prescription (7thed). Baltimore, MD: Lippincott Williams \& Wilkins.
12. American College of Sports Medicine. (2009). ACSM's Guidelines for Exercise testing and prescription. $8^{\text {th }}$ ed. Philadelpha (PA): Lippincott Willians and Wilkins.

13. Adedoyin, R.A., Mbada, C.E., Balogun, M.O., Martins, T., Akinwusi, P.O., \&Adebayo, R.A. (2008). Prevalence andPattern of Hypertension in a Semi-Urban Community in Nigeria. European Journal of Cardiovascular Prevention and Rehabilitation. 15(6):683-687

14. Wilmore, J.H andCostill, D.L. (2004): Physiology of Sport and Exercise. $3^{\text {rd }}$ Edition. Champaign Illinois: Human Kinetics Publishers, 566-602

15. Adedoyin, R.A., Mbada, C.E., Balogun, M.O., Adebayo, R.A., Martins, T., \&lsmail, S. (2009). Obesity Prevalence in Adult Residents of lle-Ife, Nigeria. Nigeria Quarterly Journal of HospitalMedicine. 19(1): 63-68.

16. Huikuri HV, Makikällio TH, Perkiomaki J. (2003). Measurement of heart rate variability by methods based on nonlinear dynamics. J Electrocardiol; 36(Suppl):95-9.

\section{Athanase}

Protogerou, CharalambosVlachopo ulos, Frederique Thomas, Yi Zhang, Bruno Pannier, Jacques Blacher,Michel E Safar (2017) : Longitudinal Changes in Mean and Pulse Pressure, and All-Cause 
Mortality: Data From 71,629 Untreated Normotensive Individuals American Journal of Hypertension, Volume 30, Issue 11, 1 November 2017, Pages 1093-1099.
18. Recalde AE, Velasques-Melendez G, Tanaka AC. De Siqueira AA (1998). Mid Upper Arm Circumference in Pregnant women and its Relationship with Birth Weight. Revista de saude Publica. 32(2): $112-117$. 